\title{
Implementation of the Perfect Plasticity Approximation with biogeochemical compartments in $\mathrm{R}$
}

\author{
Adam Erickson ${ }^{\mathrm{a}, *}$, Nikolay Strigul ${ }^{\mathrm{a}}$ \\ ${ }^{a}$ Department of Mathematics and Statistics, Washington State University \\ 14204 Salmon Creek Avenue, Vancouver, WA, 98686, USA
}

\begin{abstract}
Modeling forest ecosystems is a landmark challenge in science, due to the complexity of the processes involved and their importance in predicting future planetary conditions. While there are a number of open-source forest biogeochemistry models, few papers exist detailing the software development approach used to develop these models. This has left many forest biogeochemistry models large, opaque, and/or difficult to use, typically implemented in compiled languages for speed. Here, we present a forest biogeochemistry model from the SORTIEPPA class of models, PPA-SiBGC. Our model is based on the Perfect Plasticity Approximation with simple biogeochemistry compartments and uses empirical vegetation dynamics rather than detailed prognostic processes to drive the estimation of carbon and nitrogen fluxes. This allows our model to be used with traditional forest inventory data, making it widely applicable and simple to parameterize. We detail the conceptual design of the model as well as the software implementation in the $\mathrm{R}$ language for statistical computing. Our aim is to provide a useful tool for the biogeochemistry modeling community that demonstrates the importance of vegetation dynamics in biogeochemical models. Keywords: Perfect Plasticity Approximation, Forest ecosystem simulation, Forest biogeochemistry models, Individual-based models
\end{abstract}

\footnotetext{
* Corresponding author

Email addresses: adam.erickson@wsu.edu (Adam Erickson), nick.strigul@wsu.edu (Nikolay Strigul)
} 


\section{Motivation and Significance}

The practice of modeling ecological systems began around 1920 with a calculus model of chemical dynamics applied to the trophic interaction of herbivory [1]. The logistic growth model used was inspired by Malthusian carrying ca5 pacity [2]. The concept of Ökologie (ecology) had been formalized by Haeckel in 1866, with ecosystems soon to be coined by Tansley in 1935. Lotka-Volterra equations, a type of periodic Kolmogorov system, were next applied to fish populations [3]. Four decades later, empirical differential equations were developed to model the growth and yield of forest stands $[4,5,6]$. These models extended

10 the principle of growth tables, used in Germany since the $18^{\text {th }}$ century and in China since the $17^{\text {th }}$ century [7].

The simplicity of early forest ecosystem models reflected the computational limits of the era - models were tractable by necessity, solved by mechanical calculators or hand. Digital computers brought a landmark innovation in the 15 ability to explicitly simulate processes of forest succession at an individualtree level [8]. For the first time, direct analysis of forest dynamics theory [9] was possible. These forest 'gap' models exhausted computational resources of the era beyond the stand or landscape scale - a limitation that continues to date. Concurrently, the first one-dimensional physiological or biogeochemical process models and forest fire models were developed. Many components of modern terrestrial biosphere models were built separately and later assembled into comprehensive global modeling systems.

Until recently, the number of transistors in integrated circuits doubled every two years in accordance with Moore's Law. Despite the growth in compute, gap models remain computationally impractical for regional- or global-scale modeling. While many modeled processes are inherently serial, others are poised to greatly benefit from mass parallelization (e.g., using general-purpose graphics processing units, or GPGPUs). There is surprisingly little research in this area currently, as most modeling groups prefer to add new processes rather than optimize existing ones. Yet, there is a critical need to produce "a relatively 
simple mechanistic ecosystem model that is equitable in detail and that will run at large scales" [10]. Such a model is required to improve representation of vegetation dynamics in earth system models in order to produce more robust predictions of the global carbon cycle [11].

A lack of detailed field observations made (and still make) models of forest dynamics difficult to parameterize and validate, due to the long timescales and large number of parameters and processes involved [12]. While long-term ecological research (LTER) began formally with NSF funding of six sites in 1980, less than four decades have since passed. There are few research forests with a century of data or more. Even for sites with a long history of data (e.g., Harvard Forest), the sparsity data makes the validation of complex models non-trivial. Meanwhile, forest measurement techniques have radically advanced since the 1980s, first in the 1990s with eddy covariance flux towers and second in the 2000s with geometric point cloud models generated by laser scanning or photogrammetric computer vision (e.g., structure-from-motion). These new data sources provide detail on forest energy and biogeochemistry fluxes, canopy dynamics, species distributions, demography, and other metrics of vital importance to developing and validating new forest biogeochemistry models.

Over the past century, models of forest ecosystems grew in complexity from differential equations to detailed models of physiological and spatial processes. This progression entailed seven landmark stages of model development: $(i)$ growth-and-yield tables or equations [7]; (ii) physical soil-plant-atmosphere continuum models [13]; (iii) forest fire models [14]; (iv) forest 'gap' models [8, 12]; $(v)$ 'big-leaf' physiological process models including early land surface models $[15,16]$; (vi) hybrid and landscape models [17, 18]; (vii) 'cohort-leaf' hybrid models including ED/ED2/FATES [19, 20], LM3-PPA [21], and the simple PPA-SiBGC compartment model presented herein. Model stages $i-v$ entailed increases in complexity with each new process, resulting in the desire for new approximation schemes in stage vii models. While stage vi models expanded to include modeling spatial processes at the landscape scale, stage vii models blend physiological and demographic processes through robust gap model reductions. 
Thus, current state-of-the-art (stage vii) models follow the modeling approach advocated in the seminal works of [22] and [23]: prefer realism and generality to precision.

Models of forest ecosystems entail a number of scale- and application-specific assumptions. Historically, this has required the selection of different models for different applications or research questions [24, 25]. Terrestrial biosphere models, for example, were separated into diagnostic and prognostic models [26]. While model structure diverged over the previous four decades into specialized applications, it has converged during the past two with the development of hybrid models. The recent development of 'cohort-leaf' models has made this convergence complete, integrating aspects of each class of model, from individualbased gap models to global-scale terrestrial biosphere models. The distinction between diagnostic and prognostic models has similarly faded.

It is beneficial to comprehend that the mathematical approximations developed in stage VII models were made possible by detailed individual-based gap models. In effect, gap models were applied as generative models to produce data for difficult-to-measure dynamics needed in developing approximations. This is conceptually similar to the sim2real paradigm currently at the forefront of artificial intelligence and robotics research [27]. Using gap models as data generators was necessary due to a lack of detailed long-term observational data. In other words, the approximations are model emulators, as demonstrated in the seminal publication describing the PPA model [28, 29]. Unlike most statistical emulators (e.g., machine learning models), the PPA model is analytically tractable, thereby surpassing the requirement for an efficient model approximation providing macroscopic equations of forest dynamics [10].

In recent work [30], we demonstrated that the PPA model extended with simple biogeochemistry compartments (PPA-SiBGC) is adequate to produce model realism and precision surpassing LANDIS-II and its latest NECN biogeo-

90 chemistry model, which is an adaptation of the CENTURY model. This work is important because it demonstrates that improving the representation of vegetation dynamics in forest biogeochemistry models may yield model accuracy 
surpassing far more complex models lacking explicit canopy dynamics. Moreover, our presented model is computationally efficient, with speeds an order of magnitude faster than LANDIS-II despite being implemented in an interpreted rather than compiled language ( $\mathrm{R}$ rather than $\mathrm{C \#})$.

\section{Conceptual Framework}

In the following sections we describe the conceptual framework behind the PPA-SiBGC model.

100

105

\subsection{Perfect Plasticity Approximation}

The Perfect Plasticity Approximation (PPA) model [28] was developed based on the SORTIE individual-based model of forest ecosystems, or gap model [31]. The PPA model reduces the dimensionality of the classical SORTIE gap model by approximating the $3-\mathrm{D}$ geometric interactions of individual tree crowns at the cohort level. The PPA model was based on the observation that the inclusion of phototropism (i.e., stem-leaning) and crown plasticity (i.e., space-filling) in the crown-plastic SORTIE model, CP-SORTIE, reduced the variation in canopy join height to a negligible level [28]. Thus, assuming perfect plasticity would yield zero variation in canopy join height, allowing the canopy to simply and effectively be segmented into separate canopy layers. This property is extremely important for application in modern terrestrial biosphere models, which widely adopt one-dimensional big-leaf representation of processes. The PPA model is succinctly described by Equation 1:

$$
1=\int_{z^{*}}^{\infty} \sum_{j=1}^{k} N_{j}(z) A_{j}\left(z^{*}, z\right) d z
$$

where $k$ is the number of species, $j$ is the species index, $N_{j}(z)$ is the density of species $j$ at height $z, A_{j}\left(a^{*}, z\right)$ is the projected crown area of species $j$ at height $z$, and $d z$ is the derivative of tree height. Thus, we compute the height where the integral of tree crown area is equal to the stand ground area. This yields the theoretical $z^{*}$ height that marks the transition from above to below 
one canopy layer [28]. There may be one or many $z^{*}$ heights. The number of

theoretical $z^{*}$ heights in a stand is a function of the stand's leaf-area index, or LAI, where $n_{z^{*}}=\lfloor\mathrm{LAI}\rfloor$. Each additional closed canopy layer, including shrubs and grasses, follows the form $z^{* *}, z^{* * *}$, et cetera.

This partitioning of canopy layers allows for the use of separate coefficients or models of growth, mortality, and fecundity to be applied across the strata.

25 The first moment of these canopy layer dynamics accurately approximates the dynamics of individual-based models [28]. We extend the SORTIE-PPA model by adding a simple compartment-based representation of biogeochemistry using allometric and stoichiometric relations, along with simple prognostic (i.e., climate-driven) model of soil respiration $[32,33]$ and a constant representation of organic carbon by soil type [34].

\subsection{Allometry and Stoichiometry}

The tree allometric model and parameters were adapted from previously published research $[35,36]$. Tree height is modeled as a non-linear function of stem diameter as follows:

$$
h=1.35+\left(h_{\max }-1.35\right) \times\left(1-e^{(-1 * b * \mathrm{DBH})}\right)
$$

where $h$ is the tree height $(\mathrm{m}), h_{\max }$ is the maximum potential tree height, $\mathrm{DBH}$ is the depth-at-breast-height $(\mathrm{cm}), e$ is Euler's constant, and $b$ is an exponential decay coefficient. Tree crown radius and depth are also modeled as a function of $\mathrm{DBH}$, but are instead intercept-free linear models.

$$
d_{\text {crown }}=c d \times \mathrm{DBH}
$$

where $d p_{\text {crown }}$ is the crown depth (m) and $c d$ is the crown depth regression coefficient. The equation form is similar for crown radius:

$$
r_{\text {crown }}=c r_{1} \times \mathrm{DBH}^{c r_{2}}
$$


where $r_{\text {crown }}$ is the crown radius $(\mathrm{m})$ and, $c r_{1}$ and $c r_{2}$ are the crown radius regression coefficients. Basal area is also calculated as a function of DBH, using the forester's constant for DBH in centimeters:

$$
b a=\mathrm{DBH}^{2} \times 0.00007854
$$

National species-specific biomass equations [37] were used to model tree biomass as a function of DBH:

$$
\log \mathrm{AGB}=\beta_{0}+\beta_{1} \times \log \mathrm{DBH}
$$

where AGB is the tree aboveground biomass $(\mathrm{kg})$ and, $\beta_{0}$ and $\beta_{1}$ are regression coefficients. Empirical coefficients are used for the aboveground biomass fractions contained in stem, branch, and leaf compartments, as well as soil. Root biomass is partitioned into coarse and fine root components based on existing equations for the United States [37], following the general form:

$$
\log \text { ratio }=\beta_{0}+\beta_{1} \log \mathrm{DBH}
$$

where ratio is the biomass fraction for the root component and, $\beta_{0}$ and $\beta_{1}$ are regression coefficients. The coefficients used for coarse roots were -1.4485 for $\beta_{0}$ and -0.03476 for $\beta_{1}$. For fine roots, the coefficients were -1.8629 and 0.77534 , respectively. The biomass of each root compartment is then calculated by multiplying tree AGB by the corresponding ratio.

Tree belowground biomass is calculated as the sum of root and soil biomass, while total biomass is calculated as the sum of below- and above-ground compartments. Separate empirical biomass carbon fraction and C:N stoichiometric coefficients were used for each compartment. Thus, $\mathrm{C}$ and $\mathrm{N}$ content are fixed fractions of biomass values, based on empirical point estimates or samples from distributions.

\subsection{Soil Respiration}

In the PPA-SiBGC model, we use the simple prognostic soil respiration model of Raich et al. (2002): 


$$
R_{S}=F \times e^{\left(Q_{10} * T_{a}\right)} \times[P /(K+P)]
$$

$$
\log _{10} \mathrm{SOC}=I+\log _{10} D
$$

where $\log _{10} \mathrm{SOC}$ is the volumetric soil organic carbon density $\left(\mathrm{Mg} \mathrm{C} \mathrm{ha}{ }^{-1} \mathrm{~cm}^{-1}\right)$, $I$ is the intercept, and $D$ is the profile midpoint depth $(\mathrm{cm})$. We integrated over a range of profile depths to produce total SOC values:

$$
\log _{10} \mathrm{SOC}_{100}=\sum_{d=1}^{100} I+\log _{10} d
$$




$$
\mathrm{SOC}_{100}=10^{\log _{10} \mathrm{SOC}_{100}}
$$

Both the original SORTIE-PPA model and the PPA-SiBGC model presented herein have undergone extensive validation with field data. The SORTIE-PPA model validation is described in the original paper [28], while the PPA-SiBGC model was recently validated at two research forests for a range of metrics [30]. Despite the simplicity of the representation of biogeochemical dynamics in the PPA-SiBGC model, it outperformed LANDIS-II with NECN (i.e., CENTURY) biogeochemistry across a range of metrics and sites in the model intercomparison exercise [30].

\section{Software Description}

The PPA-SiBGC model is implemented in a standalone $\mathrm{R}$ script that is designed to be run from a command-line interface, or CLI. Since the model is implemented in $\mathrm{R}$ with no external dependencies, it can be used on any platform that R supports (e.g., Windows, Linux, MacOS). The model implementation begins by loading all input data into memory and parsing the configuration CSV file. If cohort mode is enabled, the GenerateCohorts function aggregates the individual trees into cohorts based on a predefined DBH interval (e.g., every $2 \mathrm{~cm}$ ), recording the number of trees per cohort.

Next, the allometric and stoichiometric C:N equations are applied to the individual trees or cohorts in order to calculate the initial $\mathrm{C}$ and $\mathrm{N}$ pools. The simulation is then run for each year in the defined temporal range. The overall model process is shown in Algorithm 1. 


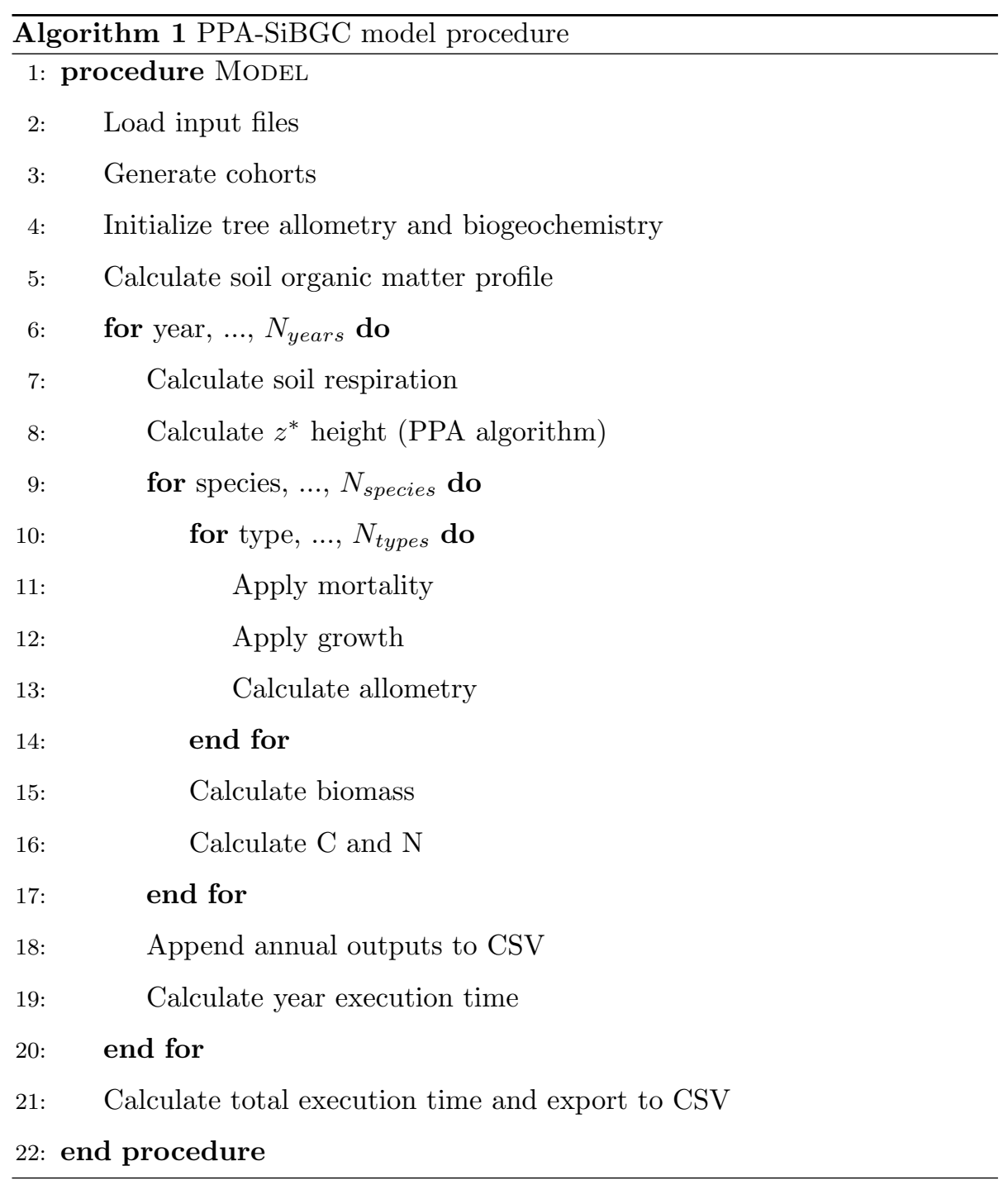


Vectorization is used where possible to accelerate the model operations. This optimization comes at no cost to the programmer in interpreted languages such as $\mathrm{R}$, as it is built into the language. Distributions such as Microsoft R Open 210 (MRO) ship with the Intel MKL optimized algebra library. An implementation of the PPA algorithm used to find the theoretical $z^{*}$ height is shown in Algorithm 2:

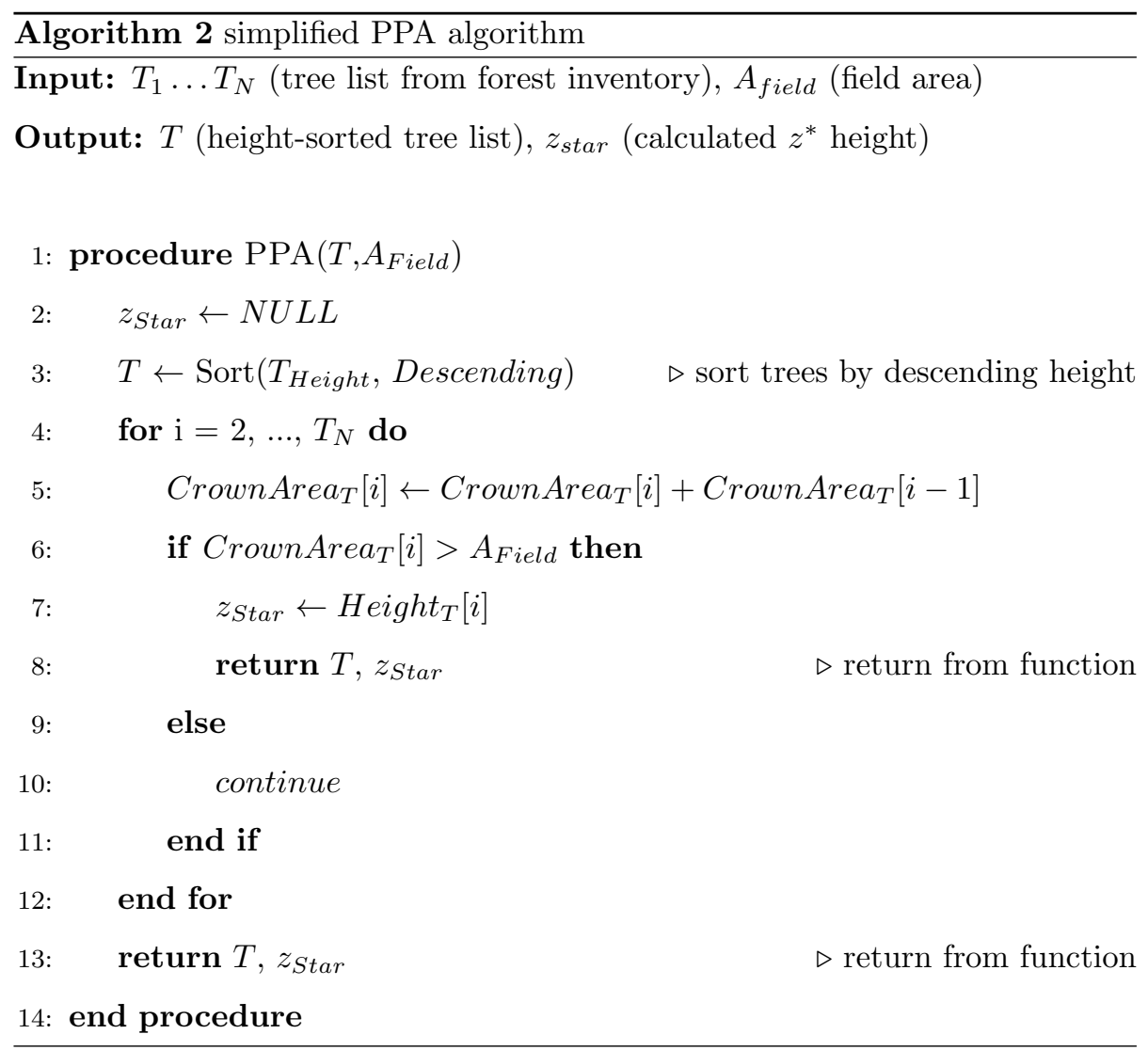


The software implementation provided is an approximation of the PPA algorithm that simplifies its calculation:

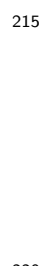

220

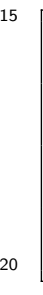

Our implementation of the soil respiration model [33] is straightforward, as shown below:

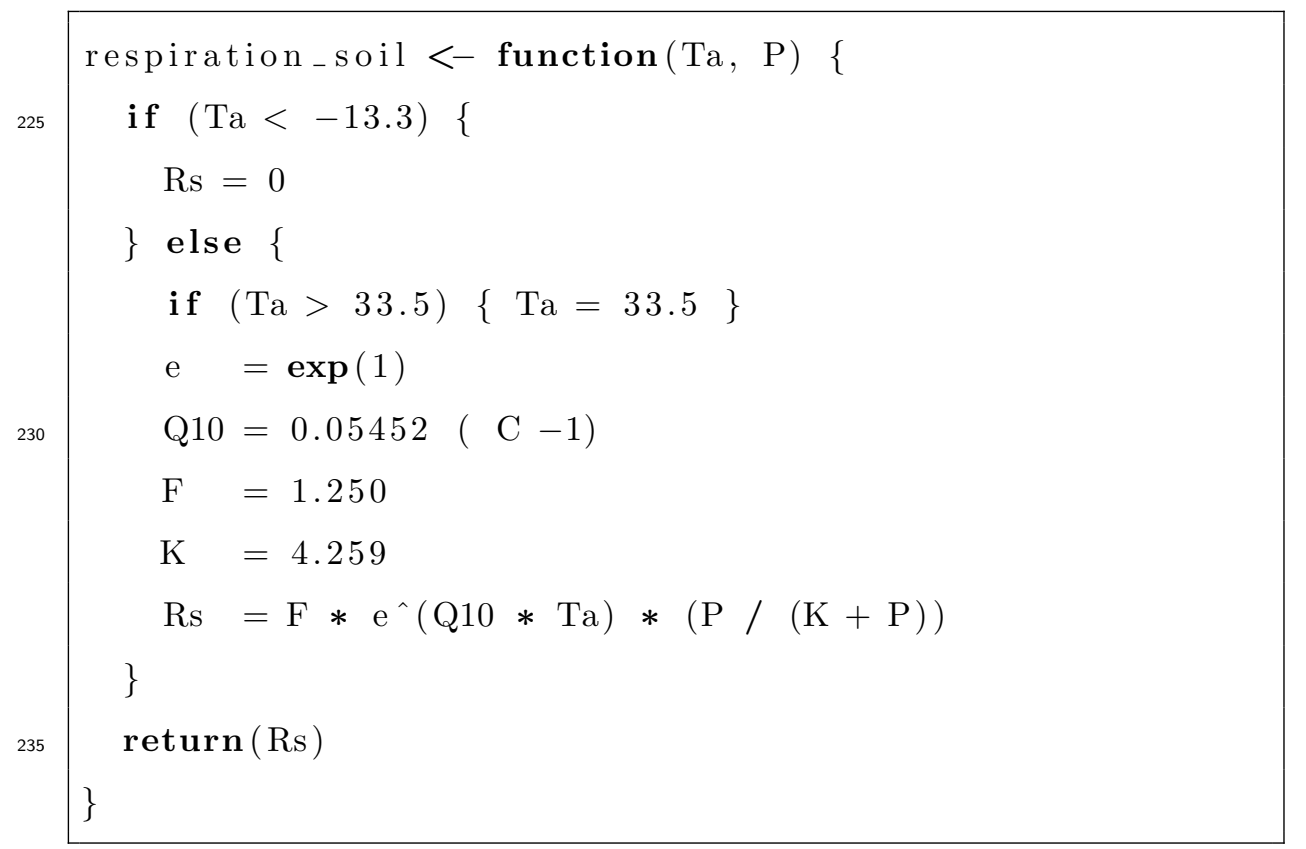

Meanwhile, our implementation of the soil organic carbon (SOC) profile model [34] is based on a lookup table containing soil classes and corresponding 240 regression model intercepts and slopes. The parameters are extracted and the linear model is applied to calculate SOC along the defined profile interval. By default, the profile interval is set to [1 . 100]. 


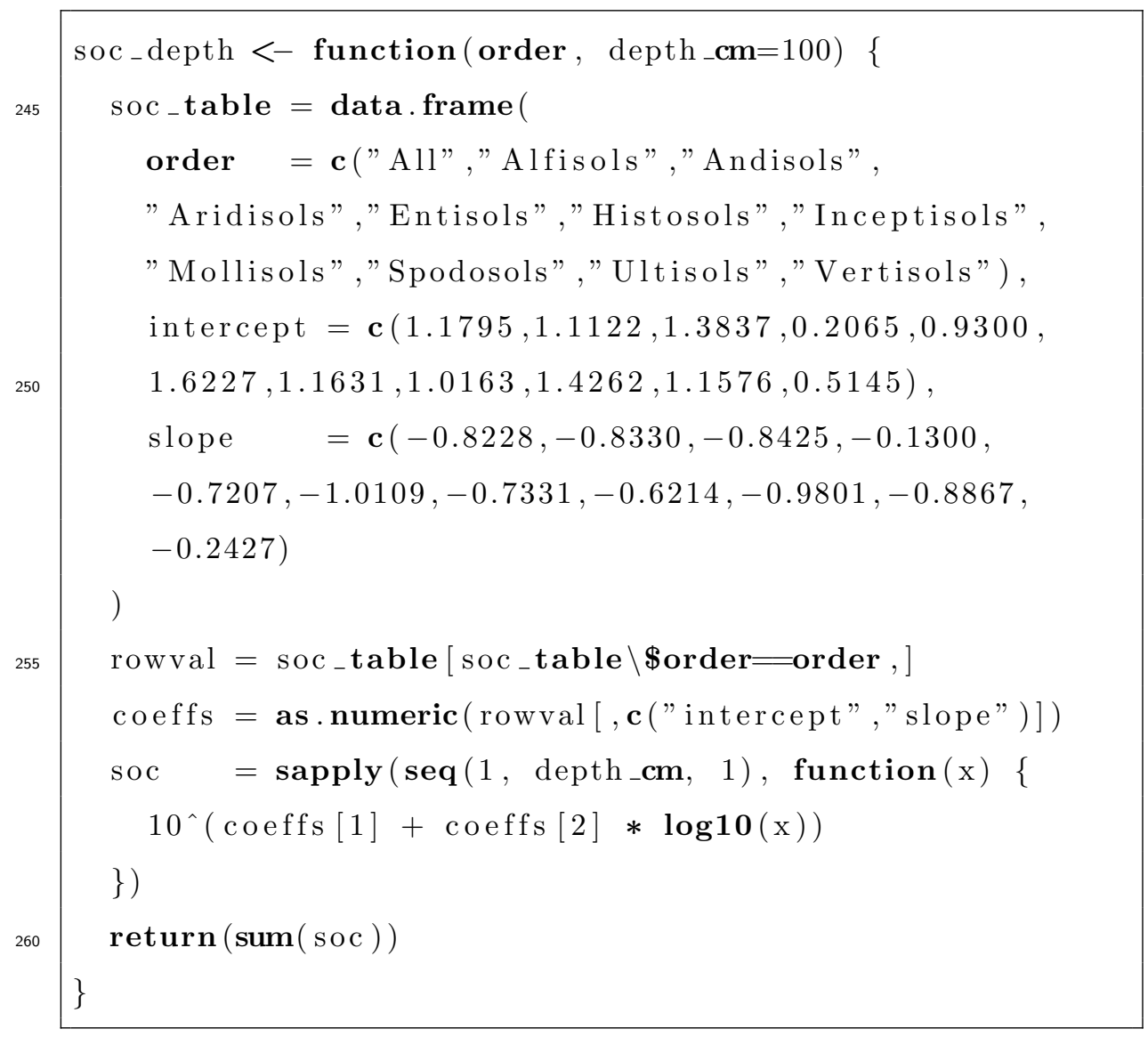

\section{Illustrative Example}

For model parameterization, validation, and comparison with the LANDISII model at Harvard Forest EMS flux tower in Massachusetts, USA and Jones Ecological Research Center RD flux tower in Georgia, USA, readers may refer to our recent model intercomparison paper [30]. An example of running the PPA-SiBGC program (ppa_v50.r) from the CLI is shown below:

Here, the Rscript executable is used with the -vanilla option to run the program within a new $\mathrm{R}$ session. Additional options include the $-w d$ flag to 
specify a working or target directory containing parameter files in a pre-defined directory structure and the -verbose flag to run the model in verbose mode for monitoring progress or debugging. The predefined directory structure expected for model input files containing parameters and drivers (i.e., climate data) is as follows:

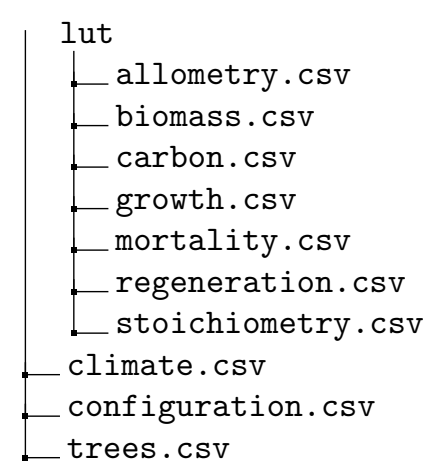

Figure 1: Directory structure of PPA-SiBGC inputs

When the simulation run is completed, the following CSV files are produced in an outputs directory within the target directory:

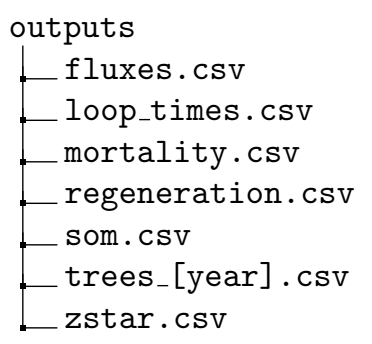

Figure 2: Directory structure of PPA-SiBGC outputs

These outputs contain the ecosystem biogeochemistry fluxes, time to complete each model iteration, cohort mortality with allometry and biogeochemistry, species regeneration, soil organic matter (SOM) pools, cohort list by simulation year with allometry and biogeochemistry, and the theoretical $z^{*}$ height by year. 


\section{Conclusions}

In conclusion, we provide a new forest biogeochemistry model, PPA-SiBGC, based on the Perfect Plasticity Approximation (PPA) algorithm in the R language of statistical computing. The program is cross-platform and is designed 
to be simple to deploy and apply. The program is designed to run from a [contract number W912HQ-18-C-0007].

\section{References}

[1] A. J. Lotka, Analytical Note on Certain Rhythmic Relations in Organic Systems, Proceedings of the National Academy of Sciences of the United

pnas.6.7.410.

URL http://www . pnas.org/content/6/7/410

[2] T. R. Malthus, An essay on the principle of population, as it affects the future improvement of society. With remarks on the speculations of $\mathrm{Mr}$. 
Godwin, M. Condorcet, and other writers., J. Johnson, London, 1798.

URL https://archive.org/details/essayonprinciplo0malt

[3] V. Volterra, Variazioni e fluttuazioni del numero d'individui in specie animali conviventi, 2nd Edition, Memoria della Reale Accademia Nazionale dei Lincei, Citta di Castello, 1926.

[4] R. E. Buckman, Technical Bulletin 1272: Growth and yield of red pine in Minnesota, Tech. rep., US Department of Agriculture, Forest Service (1962).

[5] J. L. Clutter, Compatible Growth and Yield Models for Loblolly Pine, Forest Science 9 (3) (1963) 354-371. doi:10.1093/forestscience/9.3. 354.

URL http://dx.doi.org/10.1093/forestscience/9.3.354

[6] J. W. Moser, O. F. Hall, Deriving Growth and Yield Functions for UnevenAged Forest Stands, Forest Science 15 (2) (1969) 183-188. doi:10.1093/ forestscience/15.2.183. URL http://dx.doi.org/10.1093/forestscience/15.2.183

[7] J. K. Vanclay, Modelling forest growth and yield: applications to mixed tropical forests, CABI Publishing Series, CAB International, Wallingford, UK, 1994.

URL https://books.google.com/books?id=JnhFAQAAIAAJ

[8] D. B. Botkin, J. F. Janak, J. R. Wallis, Some ecological consequences of a computer model of forest growth, Journal of Ecology 60 (3) (1972) 849-872.

[9] H. H. Shugart, A Theory of Forest Dynamics: The Ecological Implications of Forest Succession Models, Springer-Verlag, New York, 1984.

[10] G. C. Hurtt, P. R. Moorcroft, S. W. P. And, S. A. Levin, Terrestrial models and global change: challenges for the future, Global Change Biology 4 (5) (1998) 581-590. doi:10.1046/j.1365-2486.1998.t01-1-00203.x. 
URL https://onlinelibrary.wiley.com/doi/abs/10.1046/j. 1365-2486.1998.t01-1-00203.x

[11] R. A. Fisher, C. D. Koven, W. R. L. Anderegg, B. O. Christoffersen, M. C. Dietze, C. E. Farrior, J. A. Holm, G. C. Hurtt, R. G. Knox, P. J. Lawrence, J. W. Lichstein, M. Longo, A. M. Matheny, D. Medvigy, H. C. MullerLandau, T. L. Powell, S. P. Serbin, H. Sato, J. K. Shuman, B. Smith, A. T. Trugman, T. Viskari, H. Verbeeck, E. Weng, C. Xu, X. Xu, T. Zhang, P. R. Moorcroft, Vegetation demographics in Earth System Models: A review of progress and priorities, Global Change Biology 24 (1) (2018) 3554. doi:10.1111/gcb.13910.

URL https://onlinelibrary.wiley.com/doi/abs/10.1111/gcb.13910

[12] H. Bugmann, A review of forest gap models, Climatic Change 51 (2001) $259-305$.

[13] S. Manabe, Climate and the Ocean Circulation, Monthly Weather Review 97 (11) (1969) 739-774. doi:10.1175/1520-0493(1969)097<0739: CATOC> 2.3. CO; 2 .

URL https://doi.org/10.1175/1520-0493(1969)097\{\%\}3C0739: CATOC $\{\%\}$ BE2.3. COhttp://0.0.0.2

[14] R. C. Rothermal, A Mathematical Model for Predicting Fire Spread in Wildland Fuels, Tech. rep., US Forest Service (1972).

[15] R. E. Dickinson, A. Henderson-Sellers, P. J. Kennedy, M. F. Wilson, NCAR Technical Note NCAR/TN-275-+STR: Biosphere-atmosphere Transfer Scheme (BATS) for the NCAR Community Climate Model, Tech. rep., National Center for Atmospheric Research, Boulder, CO, USA (1986). doi:10.5065/D6668B58.

[16] P. J. Sellers, Y. Mintz, Y. C. Sud, A. Dalcher, A Simple Biosphere Model (SIB) for Use within General Circulation Models, Journal of the Atmospheric Sciences 43 (6) (1986) 505-531. 
doi: 10.1175/1520-0469(1986)043<0505: ASBMFU>2 . 0.CO; 2 .

URL http://dx.doi.org/10.1175/1520-0469(1986)043\{\%\}3C0505:

ASBMFU $\{\%\} 3 E 2.0 . C 02$

[17] A. Mäkelä, J. Landsberg, A. R. Ek, T. E. Burk, M. Ter-Mikaelian, G. I. Ågren, C. D. Oliver, P. Puttonen, Process-based models for forest ecosystem management: current state of the art and challenges for practical implementation, Tree Physiology 20 (5-6) (2000) 289-298. doi:10.1093/treephys/20.5-6.289.

URL http://treephys.oxfordjournals.org/content/20/5-6/289. abstract

[18] H. Kimmins, J. A. Blanco, B. Seely, C. Welham, K. Scoullar, Forecasting Forest Futures: A Hybrid Modelling Approach to the Assessment of Sustainability of Forest Ecosystems and Their Values, Taylor \& Francis Group, 2010.

URL https ://www . crcpress . com/Forecasting-Forest-Futures-A-Hybrid-Modelling-Approach-toKimmins-Blanco-Seely-Welham-Scoullar/p/book/9781844079223

[19] P. R. Moorcroft, G. C. Hurtt, S. W. Pacala, A method for scaling vegetation dynamics: The ecosystem demography model (ED), Ecological Monographs 71 (4) (2001) 557-586. doi:10.1890/0012-9615(2001)071 [0557:AMFSVD] 2.0. $\mathrm{CO} ; 2$. URL http://dx.doi.org/10.1890/0012-9615(2001)071 [0557:AMFSVD] 2.0. $\mathrm{CO} ; 2$

[20] D. Medvigy, S. C. Wofsy, J. W. Munger, D. Y. Hollinger, P. R. Moorcroft, Mechanistic scaling of ecosystem function and dynamics in space and time: Ecosystem Demography model version 2, Journal of Geophysical Research: Biogeosciences 114 (G1). doi:10.1029/2008JG000812.

URL http://dx.doi.org/10.1029/2008JG000812

[21] E. S. Weng, S. Malyshev, J. W. Lichstein, C. E. Farrior, R. Dybzinski, T. Zhang, E. Shevliakova, S. W. Pacala, Scaling from individual trees to 
forests in an Earth system modeling framework using a mathematically tractable model of height-structured competition, Biogeosciences 12 (9) (2015) 2655-2694. doi:10.5194/bg-12-2655-2015.

URL https://www.biogeosciences.net/12/2655/2015/

[22] R. Levins, The Strategy of Model Building in Population Biology, American Scientist 54 (4) (1966) 421-431.

[23] R. MacArthur, R. Levins, Competition, habitat selection, and character displacement in a patchy environment, Proceedings of the National Academy of Sciences 51 (6) (1964) 1207-1210. doi:10.1073/pnas.51.6. 1207.

URL http://www .pnas.org/content/51/6/1207

[24] H. Kimmins, J. A. Blanco, B. Seely, C. Welham, K. Scoullar, J. P. (Hamish) Kimmins, J. A. Blanco, B. Seely, C. Welham, K. Scoullar, Complexity in modelling forest ecosystems: How much is enough?, Forest Ecology and Management 256 (10) (2008) 1646-1658. doi:https://doi.org/10.1016/j.foreco.2008.03.011. URL http://www.sciencedirect.com/science/article/pii/ S0378112708002478http://linkinghub.elsevier.com/retrieve/ $\mathrm{pii} / \mathrm{S} 0378112708002478$

[25] W. Jin, H. S. He, F. R. T. III, Are more complex physiological models of forest ecosystems better choices for plot and regional predictions?, Environmental Modelling \& Software 75 (2016) 1-14. doi:https://doi.org/10.1016/j.envsoft.2015.10.004.

URL http://www.sciencedirect.com/science/article/pii/ S1364815215300621

[26] M. Heimann, G. Esser, A. Haxeltine, J. Kaduk, D. W. Kicklighter, W. Knorr, G. H. Kohlmaier, A. D. McGuire, J. Melillo, B. Moore, R. D. Otto, I. C. Prentice, W. Sauf, A. Schloss, S. Sitch, U. Wittenberg, 
G. Würth, Evaluation of terrestrial carbon cycle models through simulations of the seasonal cycle of atmospheric $\mathrm{CO} 2$ : First results of a model intercomparison study, Global Biogeochemical Cycles 12 (1) (1998) 1-24. doi:10.1029/97GB01936.

URL https://agupubs.onlinelibrary.wiley.com/doi/abs/10.1029/ 97GB01936

[27] E. Tzeng, C. Devin, J. Hoffman, C. Finn, P. Abbeel, S. Levine, K. Saenko, T. Darrell, Adapting Deep Visuomotor Representations with Weak Pairwise Constraints, ArXiv e-printsarXiv:1511.07111.

[28] N. Strigul, D. Pristinski, D. Purves, J. Dushoff, S. Pacala, Scaling from trees to forests: tractable macroscopic equations for forest dynamics, Ecological Monographs 78 (4) (2008) 523-545. doi:10.1890/08-0082.1.

URL http://dx.doi.org/10.1890/08-0082.1

[29] N. Strigul, Individual-Based Models and Scaling Methods for Ecological Forestry: Implications of Tree Phenotypic Plasticity, in: J. M. Garcia, J. J. D. Casero (Eds.), Sustainable Forest Management, IntechOpen, Rijeka, 2012, Ch. 20, pp. 359-384. doi:10.5772/29590.

URL https://doi.org/10.5772/29590

[30] A. Erickson, N. Strigul, A forest biogeochemistry model intercomparison on the East Coast of the United States, bioRxivdoi:10.1101/464578.

URL https://www.biorxiv.org/content/early/2018/11/07/464578

[31] S. W. Pacala, C. D. Canham, J. Saponara, J. A. Silander, R. K. Kobe, E. Ribbens, Forest models defined by field measurements: estimation, error analysis and dynamics, Ecological Monographs 66 (1) (1996) 1-43. doi: $10.2307 / 2963479$.

URL http://dx.doi.org/10.2307/2963479

[32] J. W. Raich, C. S. Potter, Global patterns of carbon dioxide emissions from soils, Global Biogeochemical Cycles 9 (1) (1995) 23-36. doi:10. 
1029/94GB02723.

URL https://agupubs.onlinelibrary.wiley.com/doi/abs/10.1029/ 94GB02723

[33] J. W. Raich, C. S. Potter, D. Bhagawati, Interannual variability in global soil respiration, 198094, Global Change Biology 8 (8) (2002) 800812. arXiv:https://onlinelibrary.wiley.com/doi/pdf/10.1046/j. 1365-2486.2002.00511.x, doi:10.1046/j.1365-2486.2002.00511.x.

URL https://onlinelibrary.wiley.com/doi/abs/10.1046/j. $1365-2486.2002 .00511 . x$

[34] G. M. Domke, C. H. Perry, B. F. Walters, L. E. Nave, C. W. Woodall, C. W. Swanston, Toward inventory-based estimates of soil organic carbon in forests of the united states, Ecological Applications 27 (4) (2017) 1223-1235. arXiv:https://esajournals.onlinelibrary.wiley.com/ doi/pdf/10.1002/eap.1516, doi:10.1002/eap.1516.

URL https://esajournals.onlinelibrary.wiley.com/doi/abs/10. 1002/eap. 1516

[35] C. D. Canham, K. D. Coates, P. Bartemucci, S. Quaglia, Measurement and modeling of spatially explicit variation in light transmission through interior cedar-hemlock forests of British Columbia, Canadian Journal of Forest Research 29 (11) (1999) 1775-1783. doi:10.1139/x99-151.

[36] B. S. Case, H. L. Buckley, A. A. Barker-Plotkin, D. A. Orwig, A. M. Ellison, When a foundation crumbles: forecasting forest dynamics following the decline of the foundation species Tsuga canadensis, Ecosphere 8 (7) (2017) e01893. doi:10.1002/ecs2.1893.

URL https://esajournals.onlinelibrary.wiley.com/doi/abs/10. $1002 /$ ecs 2.1893

[37] D. C. Chojnacky, L. S. Heath, J. C. Jenkins, Updated generalized biomass equations for North American tree species, Forestry: An International Jour- 
nal of Forest Research 87 (1) (2014) 129-151. doi:10.1093/forestry/ cpt053.

URL http://dx.doi.org/10.1093/forestry/cpt053

[38] C. Eloy, M. Fournier, A. Lacointe, B. Moulia, Wind loads and competition for light sculpt trees into self-similar structures, Nature Communications 8 (1) (2017) 1014. doi:10.1038/s41467-017-00995-6.

URL https ://doi .org/10.1038/s41467-017-00995-6 